
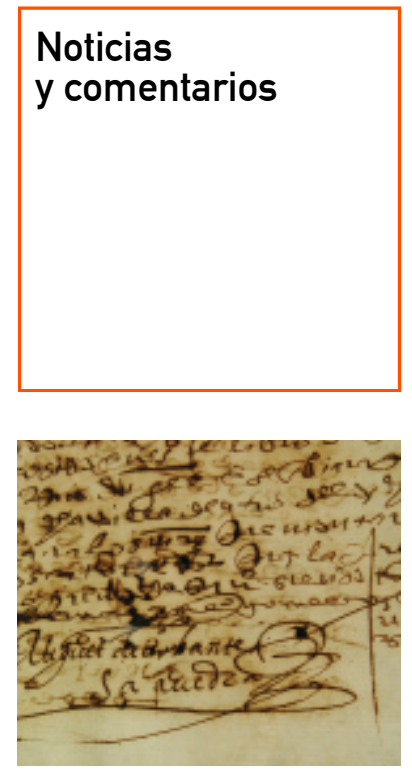

Firma del recaudador Miguel de Cervantes en el Libro de Acuerdos Capitulares del Archivo Histórico Municipal de La Palma del Condado (Huelva)

\title{
El IAPH contribuye a la conmemoración del Año Cervantes con la restauración de varios documentos
}

Con motivo del $4^{\circ}$ Centenario de la publicación de la primera parte del clásico "Don Quijote de La Mancha" de Miguel de Cervantes, el Instituto Andaluz del Patrimonio Histórico de la Consejería de Cultura se suma a las iniciativas que se están llevando a cabo para conmemorar la significativa efeméride, realizando a lo largo del año la restauración de varios documentos cervantinos conservados en diversos archivos de la comunidad autónoma andaluza.

El primero de ellos se localiza en el Libro de Acuerdos Capitulares del Archivo Histórico Municipal de La Palma del Condado (Huelva). Con fecha de 25 de julio de 1593 da cuenta de la presencia de Miguel de Cervantes como recaudador en nombre del Comisario General, Miguel de Oviedo, quien le encomienda el trabajo de cobro de tasas atrasadas. En La Palma del Condado firma el recibo que aceptaba lo acordado entre el Comisario Real y el Concejo de la villa, que ascendia a cien fanegas de trigo.

Esta acta es un traslado cosido en el mencionado Libro de Acuerdos, legajo 4 del fondo municipal, por el cual el escribano público de Cabildo, Juan Pinto, da fe y autoriza a enviar dicha cantidad de trigo en los siguientes quince dias por un montante total de catorce reales, tal como establece la Pragmática Real.

La intervención ha consistido en la extracción y descosido del volumen de cuatro bifolios en grave estado de conservación. Presentaban nu- merosas alteraciones de origen físico-químicas y mecánicas, siendo las más significativas el alto grado de corrosión de las tintas manuscritas de composición metaloácida.

En primer lugar se realizó una limpieza superficial mecánica y una fijación auxiliar antes de proceder a los procesos húmedos. Se lavaron y desacidificaron los documentos con objeto de elevar los valores de $\mathrm{pH}$, inicialmente muy bajos, y para aportarles una reserva alcalina. Posteriormente se llevó a cabo la reintegración mecánica del soporte debido a las numerosas y diminutas lagunas que presentaban los documentos. Finalmente, se reaprestaron y laminaron mecánicamente por el reverso de los folios.

La intervención se dio por concluida una vez fue ultimado el cosido provisional al volumen hasta que se acometa la intervención integral de la obra.

Con estos trabajos se ha logrado la consolidación material de los documentos recuperando la legibilidad de la imagen artística y el restablecimiento de la unidad potencial y funcional de la misma.

Mónica Santos Navarrete

Maria Campoy Naranjo

Centro de Intervención del IAPH

\section{¿Tienes algo que decir sobre patrimonio y empleo?}

PH54 (julio 2005) analizará la realidad del mercado laboral vinculado al patrimonio histórico/cultural. Como base para la participación de los lectores proponemos las siguientes preguntas:

1.¿Preparan para el empleo las titulaciones y postgrados universitarios asociados tradicionalmente al patrimonio en cualquiera de sus modalidades?

2.¿Están definidos los perfiles profesionales en el ámbito del patrimonio?

3.El patrimonio cultural/ turismo cultural se considera un motor de desarrollo a nivel local. ¿Ese desarrollo ha supuesto la generación considerable de empleo? ¿Qué tipo de empleo?

Fecha límite y dirección de envío: 1 de mayo, al correo-e.:

boletin.iaph.ccul@juntadeandalucia.es 